\title{
POSSIBILIDADES DE ASSINATURA, REGISTRO E PROTESTO ELETRÔNICOS DOS TÍTULOS DE CRÉDITO DO AGRONEGÓCIO
}

\author{
Alexandre Scigliano Valerio ${ }^{1}$ \\ Fabio Fernandes Neves Benfatti ${ }^{2}$
}

\section{RESUMO}

Leis e atos normativos, a maioria dos quais bastante recentes, dispõem sobre a assinatura eletrônica de documentos em geral e dos títulos de crédito do agronegócio em especial. A par disso, provimentos do Conselho Nacional de Justiça, igualmente recentes, permitem a prestação do serviço notarial e registral de forma eletrônica. Através da análise e inédita justaposição de tais atos normativos, o objetivo do presente trabalho é explorar as novas possibilidades jurídicas de assinatura, registro e protesto eletrônicos dos títulos de crédito do agronegócio, orientando agentes do agronegócio, notários e registradores.

Palavras-chave: Títulos de crédito. Agronegócio. Assinatura eletrônica. Registros Públicos. Protesto.

\section{POSSIBILITIES OF ELECTRONIC SIGNATURE, REGISTRATION AND PROTEST OF AGRIBUSINESS CREDIT BONDS}

\begin{abstract}
Laws and normative acts, most of which are very recent, provide for the electronic signature of documents in general and agribusiness credit bonds in particular. In addition, provisions of the National Council of Justice, equally recent, allow the provision of notary and registry services electronically. Through the analysis and unprecedented juxtaposition of such normative acts, the objective of this work is to explore the new legal possibilities of electronic signature, registration and protest of agribusiness credit bonds, guiding agribusiness agents, notaries and registrars.
\end{abstract}

Keywords: Credit bonds. Agribusiness. Electronic signature. Public registration. Protest.

\section{INTRODUÇÃO}

Em 2020, o agronegócio foi responsável por 26,6\% do Produto Interno Bruto brasileiro (USP, 2021). Trata-se de setor que demanda alto grau de investimentos. Os títulos de crédito permitem a circulação de riquezas de forma segura e eficiente. A legislação prevê,

\footnotetext{
${ }^{1}$ Doutor em Direito Econômico pela UFMG. Mestrando em Direito, Sociedade e Tecnologias pela Escola de Direito das Faculdades Londrina. Especialista em Direito Notarial e Registral e Direito Registral Imobiliário. $1^{\circ}$ Tabelião de Protesto de Maringá. E-mail: asvalerio1@uol.com.br

${ }^{2}$ Doutor em Direito Político e Econômico pela Universidade Presbiteriana Mackenzie (UPM). Graduação em Administração. Graduação em Direito e Mestrado em Direito Negocial, ambos pela Universidade Estadual de Londrina (UEL). Pós-Doutorado pela Università degli Studi di Messina, UNIME, Itália. E-mail: benfatti@hotmail.com
} 
assim, diversas espécies de títulos de crédito do agronegócio - aqui denominados TCAgro com inúmeras vantagens ${ }^{3}$.

Diversas leis recentes e ainda pouco estudadas dispõem sobre a assinatura eletrônica de documentos em geral e dos TCAgro em particular: (a) a Lei Federal 14.063/2020, confirmando a MP 2.200-2/2001, confere validade jurídica aos documentos nato-digitais; (b) a mesma Lei, aliada aos arts. 3', "caput", X, e 18, da Lei Federal 13.874/2019, e regulamentada pelo Decreto Federal 10.278/2020, confere validade jurídica aos documentos digitalizados; (c) a Lei Federal 13.986/2020, também chamada "Lei do Agro", prevê a emissão, escrituração, custódia, registro e depósito centralizado dos TCAgro, sempre de forma eletrônica. A par disso, outras alterações legislativas, bem como atos normativos do Conselho Nacional de Justiça (CNJ), permitem a prestação de serviços notariais e registrais de forma eletrônica, incluindo o registro eletrônico nos ofícios de registro de imóveis e de títulos e documentos - registro que é condição para a constituição de diversas garantias reais contidas nos TCAgro - e o protesto eletrônico.

Através da análise e inédita justaposição de tais leis e atos normativos, o objetivo do presente artigo é estudar as novas possibilidades jurídicas de assinatura, registro e protesto eletrônicos dos TCAgro, orientando agentes do agronegócio, notários e registradores.

O Artigo é dividido em duas partes. Na primeira, serão expostos, de forma sucinta e sistematizada, os diversos TCAgro. Na segunda, serão expostas as possibilidades acima mencionadas. Observe-se que praticamente não há estudos sobre registro e protesto eletrônicos.

\section{TÍTULOS DE CRÉDITO DO AGRONEGÓCIO}

\subsection{Quais são; dispositivos ou atos normativos de regência}

Serão estudados aqui os seguintes TCAgro, os quais são regidos, precipuamente, pelos seguintes dispositivos ou atos normativos: (a) cédula de crédito rural (CR): arts. $9^{\circ}$ a 41 e 55 a 78 do Decreto-Lei Federal 167, de 14 de fevereiro de 1967 (doravante “DL 167”); (b) nota promissória rural (NPR): arts. 42 a 45 e, de modo geral, arts. 71 a 78 do DL 167; (c) duplicata rural (DR): arts. 46 a 54 e, de modo geral, arts. 71 a 78 do DL 167; (d) cédula de

\footnotetext{
${ }^{3}$ Umas das vantagens é permitir um maior financiamento e a diversificação de suas fontes, incluindo os agentes privados (NEVES, 2011).
} 
produto rural (CPR): Lei Federal 8.929, de 22 de agosto de 1994 (doravante "Lei 8.929”); (e) certificado de depósito agropecuário (CDA) e warrant agropecuário (WA): arts. $1^{\circ}$ a 22 da Lei Federal 11.076, de 30 dezembro de 2004 (doravante "Lei 11.076"); (f) certificado de direitos creditórios do agronegócio (CDCA): arts. 23 a 25, 28 a 35-D e 41 a 44 da Lei 11.076; (g) letra de crédito do agronegócio (LCA): arts. 23, 26 a 35-D e 41 a 44 da Lei 11.076; (h) certificado de recebíveis do agronegócio (CRA): arts. 23 e 36 a 44 da Lei 11.076; (i) cédula imobiliária rural (CIR): arts. 17 a 29 da Lei Federal 13.986, de 7 de abril de 2020 (doravante, "Lei 13.986" ou "Lei do Agro").

\section{2}

\section{Definições e características}

A CR é uma promessa de pagamento em dinheiro (art. 9, "caput”, do DL 167) quando a finalidade do crédito concedido é financiar uma atividade ruralista (arts. 14, IV, 20, IV, 25, IV, e 27, IV, do mesmo DL).

A NPR é a nota promissória emitida:

nas vendas a prazo de bens de natureza agrícola, extrativa ou pastoril, quando efetuadas diretamente por produtores rurais ou por suas cooperativas; nos recebimentos, pelas cooperativas, de produtos da mesma natureza entregues pelos seus cooperados, e nas entregas de bens de produção ou de consumo, feitas pelas cooperativas aos seus associados [...]. (art. 42, "caput", do DL 167)

A DR é a duplicata emitida "nas vendas a prazo de quaisquer bens de natureza agrícola, extrativa ou pastoril, quando efetuadas diretamente por produtores rurais ou por suas cooperativas" (art. 46, “caput”, do DL 167).

A CPR não é uma promessa de pagamento em dinheiro, e sim de entrega de produtos

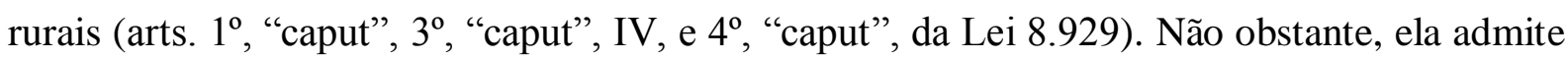
uma modalidade em que representa, sim, uma promessa de pagamento em dinheiro, mas cujo valor é definido em função da quantidade ou qualidade de um produto: trata-se da CPR com liquidação financeira (arts. $1^{\circ}, \S 1^{\circ}, 4^{\circ}$, “caput”, e $4^{\circ}$-A da mesma Lei). Ela é emitida por produtor rural, cooperativa agropecuária, associação de produtores rurais ou outras pessoas, nos termos do art. $2^{\circ}$, “caput" e $\S 1^{\circ}$, da mesma Lei. O título não representa, necessariamente, uma operação de financiamento rural (MAMEDE, 2019, p. 325); ele implica, na prática, uma venda antecipada da produção rural (COSTA, 2008, p. 473; NEVES, 2002, p. 13), mas o STJ 
já o admitiu seu uso como instrumento de "hedge", para proteção "contra os riscos de flutuação de preços no mercado futuro" (REsp 1.023.083/GO, j. 15.04.2010).

O CDA é título "representativo de promessa de entrega de produtos agropecuários, seus derivados, subprodutos e resíduos de valor econômico, depositados" em armazéns destinados à atividade de guarda e conservação de produtos agropecuários e certificados pelo governo federal (art. $1^{\circ}, \S 1^{\circ}$, da Lei 11.076 c/c art. $2^{\circ}$, "caput”, da Lei Federal 9.973, de 29 de maio de 2000). Já o WA é título "representativo de promessa de pagamento em dinheiro que confere direito de penhor sobre o CDA correspondente, assim como sobre o produto nele descrito" (art. $1^{\circ}, \S 2^{\circ}$, da Lei 11.076). Ainda segundo a Lei 11.076, “o CDA e o WA são títulos unidos, emitidos simultaneamente pelo depositário, a pedido do depositante, podendo ser transmitidos unidos ou separadamente" (art. $\left.1^{\mathrm{o}}, \S 3^{\circ}\right)$.

O CDCA, a LCA e o CRA devem ser lastreados em:

[...] direitos creditórios originários de negócios realizados entre produtores rurais, ou suas cooperativas, e terceiros, inclusive financiamentos ou empréstimos, relacionados com a produção, a comercialização, o beneficiamento ou a industrialização de produtos ou insumos agropecuários ou de máquinas e implementos utilizados na atividade agropecuária. (art. 23, $\S 1^{\circ}$, da Lei 11.076$)$

O CDCA é título nominativo, de livre negociação, representativo de promessa de pagamento em dinheiro e emitido exclusivamente por cooperativas agropecuárias e outras pessoas jurídicas que exerçam a atividade de comercialização, beneficiamento ou industrialização de produtos, insumos, máquinas e implementos agrícolas, pecuários, florestais, aquícolas e extrativos (art. 24, "caput” e $\S 1^{\text {o }}$, da mesma Lei).

A LCA é título nominativo, de livre negociação, representativo de promessa de pagamento em dinheiro e emitido exclusivamente por instituições financeiras públicas ou privadas (art. 26 da Lei 11.076).

O CRA tem origem em um Termo de Securitização de Direitos Creditórios do Agronegócio (cf. art. 37, "caput”, VIII, da Lei 11.076). Segundo o art. 40 da Lei, "a securitização de direitos creditórios do agronegócio é a operação pela qual tais direitos são expressamente vinculados à emissão de uma série de títulos de crédito", daí surgindo referido Termo. A securitização é feita por companhias securitizadoras, que são "instituições não financeiras constituídas sob a forma de sociedade por ações" e que têm por finalidade "a aquisição e securitização desses direitos e a emissão e colocação de Certificados de 
Recebíveis do Agronegócio no mercado financeiro e de capitais” (art. 38). A partir do Termo, nasce o CRA, que é título nominativo, de livre negociação, representativo de promessa de pagamento em dinheiro e emitido exclusivamente pelas companhias securitizadoras (art. 36).

A CIR vincula-se a um patrimônio rural submetido ao regime de afetação, nos termos dos arts. $7^{\circ}$ a 16 da Lei 13.986. Nesse regime, o proprietário separa, de seu patrimônio geral, um ou mais imóveis rurais, no todo ou parte, para fins de prestação de garantia por meio de CPR ou CIR (art. $7^{\circ}$ ). A CIR é título nominativo, transferível e de livre negociação, representativo de promessa de pagamento em dinheiro, decorrente de operação de crédito de qualquer modalidade, garantida pela obrigação de entregar, em favor do credor, bem imóvel rural, ou fração deste, vinculado ao patrimônio rural em afetação (art. 17 da Lei 13.986; cf. também art. 21, “caput”). Portanto, o emitente da CIR é proprietário de imóvel rural, pessoa natural ou jurídica, que houver constituído patrimônio rural em afetação (art. 18, “caput”).

\subsection{Natureza de título de crédito}

Todo os TCAgro são definidos legalmente como títulos de crédito ${ }^{4}$ ou títulos líquidos e certos e, portanto, como títulos executivos extrajudiciais [cf. art. 784, XII, do Código de Processo Civil (CPC)]. Nesse sentido: arts. 10, "caput", 41, 44 e 52 do DL 167 (CR, NPR e DR); arts. $4^{\circ}$, "caput", $4^{\circ}-\mathrm{A}, \S \S 1^{\circ}$ e $2^{\circ}$, e 15 da Lei $8.929(\mathrm{CPR})$; arts. $1^{\circ}, \S \S 1^{\circ}, 2^{\circ}$ e $4^{\circ}, 9^{\circ}, \S 1^{\circ}, 23$, “caput", 24, “caput”, 26, “caput”, e 36, “caput”, da Lei 11.076 (CDA/WA, CDCA, LCA e CRA); e arts. 17, “caput”, e 21, “caput”, da Lei 13.986 (CIR).

Aplicam-se as normas de Direito Cambial, inclusive emissão ou saque, endosso e aval, com as exceções ou modificações previstas em lei (art. 60 do DL 167; art. 10 da Lei 8.929; arts. $2^{\circ}$ e 44 da Lei 11.076; arts. 21, § $2^{\circ}$, e 29 da Lei 13.986), bem como aquelas derivadas da sistemática de escrituração, custódia, registro ou depósito centralizado eletrônicos (cf. seção 2.6 abaixo).

Como em todos os títulos de crédito, não há necessidade de reconhecimento de firma (SERRA; SERRA, 2013, p. 172) ou testemunhas (MAMEDE, 2019, p. 241 e 247), o que foi reforçado no art. $14, \S \S 3^{\circ}$ e $6^{\circ}$, do DL 167.

\subsection{Garantias}

\footnotetext{
${ }^{4}$ As cédulas de crédito rural são legalmente classificadas como títulos "civis" (art. 10 do DL 167), o que é criticado por Martins (2016, p. 505-506) e Costa (2008, p. 465).
} 
Os TCAgro podem ser emitidos tanto sem garantia como conter ou instituir, em seu próprio instrumento, garantias. As garantias podem ser reais ou fidejussórias. No caso de garantias reais sobre bens imóveis, como há todo um regramento próprio, não há necessidade de escritura pública, excepcionando-se a norma geral do art. 108 do CC (cf. COSTA, 2008, p. 463; REQUIÃO, 2012).

A CR admite as seguintes modalidades: a) cédula rural pignoratícia, quando nela há constituição de penhor; b) cédula rural hipotecária: quando nela há constituição de hipoteca; c) cédula rural pignoratícia e hipotecária: quando nela há constituição de penhor e hipoteca; d) nota de crédito rural: quando não há garantia real (cf. art. $9^{\circ}$ do DL 167). No caso da nota de crédito rural, e na prática, há, normalmente, garantia pessoal (aval, conforme art. 60, "caput”, do DL); além disso, o crédito documentado por nota de crédito rural tem privilégio especial (art. 28 do DL, que faz referência ao art. 1.563 do anterior CC; o privilégio especial é previsto no atual CC em seu art. 964).

A NPR e a DR não têm garantia real nem pessoal, exceto nos casos do art. $60, \S \S 2^{\circ}$ a $4^{\mathrm{o}}$, do DL $167^{5}$. Elas gozam de privilégio especial (arts. 45 e 53 do DL 167).

A CPR admite qualquer tipo de garantia (arts. $3^{\circ}$, "caput", VI, e $5^{\circ}$ a $8^{\circ}$ da Lei 8.929). Cédulas que constituem alienação fiduciária em garantia são denominadas "cédulas fiduciárias" (MAMEDE, 2019, p. 239). Expressamente, a CPR pode ter como garantia o patrimônio rural em afetação (art. $7^{\circ}$, parágrafo único, da Lei 13.986).

O CDA, por sua natureza, é garantido pelos produtos depositados (os quais devem estar livres e desembaraçados de quaisquer ônus, nos termos do art. $6^{\circ}, \S 1^{\circ}$, I, da Lei 11.076), enquanto o WA é garantido pelo penhor do CDA e dos produtos nele descritos (art. $1^{\circ}, \S 2^{\circ}$, da mesma Lei). Outras garantias podem ser oferecidas (art. 5 $5^{\circ}$ " caput", XIV, da mesma Lei, e art. $6^{\circ}$, § $3^{\circ}$, da Lei Federal 9.973, de 29 de maio de 2000).

O CDCA e a LCA conferem direito de penhor sobre os direitos creditórios a eles vinculados, independentemente de convenção, registro e notificação do devedor (art. 32, “caput”, da Lei 11.076); é admitida, ainda, a pactuação de qualquer outro tipo de garantia (art. 33, "caput", da mesma Lei). No lugar do penhor, pode haver, ainda, cessão fiduciária de tais direitos, o que vale, inclusive, para o CRA (art. 41 da mesma Lei).

\footnotetext{
${ }^{5}$ As restrições dos $\S \S 2^{\circ}$ a $4^{\circ}$ do art. 60 do DL 167 valem apenas para as NPR e DR e não para as CR, conforme decidiu o STJ no REsp 1.315.702/MS, j. 10.03.2015.
} 
A CIR é garantida pelo patrimônio rural em afetação que está em sua origem (arts. 17 e $18, \S 1^{\circ}$, da Lei 13.986). Vencida e não paga a CIR, o credor transferirá, para sua titularidade, o registro da propriedade da área rural que constitui o patrimônio rural em afetação, ou de sua fração, vinculado à CIR no cartório de registro de imóveis correspondente (art. 28). A CIR também poderá ser garantida por terceiros, inclusive por instituição financeira ou por seguradora (art. 20) e receber aval (art. $21, \S 1^{\circ}$ ).

Os bens ou direitos a que se referem os TCAgro, ou que são, por meio deles, dados em garantia, não podem sofrer medidas constritivas tais como embargo, penhora, sequestro ou arresto, devendo tais medidas incidir sobre os títulos (art. 69 do DL 167; art. 18 da Lei 8.929; arts. 12 e 34 da Lei 11.076).

\section{$2.5 \quad$ Requisitos formais}

Dispositivos preveem os requisitos ou elementos que devem conter os TCAgro: Assim: (a) arts. 14, “caput”, 20, “caput”, 25, 27, 43 e 48 do DL 167 (CR, NPR e DR); (b) art. 3', “caput”, da Lei 8.929 (CPR); (c) arts. 5, 25, “caput”, 27, “caput”, e 37, “caput”, da Lei 11.076 (CDA/WA, CDCA, LCA e CRA); (d) art. 22, “caput”, da Lei 13.986 (CIR).

\subsection{Forma: cartular X escritural}

Os TCAgro podem ser emitidos sob a forma cartular ou escritural ${ }^{6}$ (a exceção é o CRA, que só admite a forma escritural, nos termos do art. 37, § $1^{\circ}$, da Lei 11.076). A Lei do Agro alterou o DL 167, a Lei 8.929 e a Lei 11.076 para: (a) possibilitar a assinatura eletrônica da CR, da NPR, da DR e da CPR (arts. 14, IX, 20, IX, 25, X, 27, VIII, 43, VIII, e 48, XI, do DL 167; art. $3^{\circ}$, VIII, da Lei 8.929); (b) possibilitar a emissão escritural desses mesmos títulos (arts. 10-A, “caput”, 42, § 2º e 46, parágrafo único, do DL 167; art. 3-A, “caput”, da Lei 8.929); (c) criar, para todos os TCAgro, uma nova sistemática de escrituração, custódia, registro e depósito centralizado eletrônicos, visando à maior segurança e eficiência em sua negociação e, consequentemente, ampliação do crédito.

Os atos de escrituração, custódia, registro e depósito centralizado eletrônicos são realizados por entidades autorizadas e fiscalizadas pelo Banco Central do Brasil ou pela

\footnotetext{
${ }^{6}$ Títulos escriturais são aqueles mantidos em contas de depósito, em nome dos titulares, por instituições autorizadas, sem emissão de certificados (cf. arts. 34 e 35 da Lei Federal 6.404, de 15 de dezembro de 1976).
} 
Comissão de Valores Mobiliários, no âmbito de suas competências (arts. 10-A, 10-C, 42, § 2 e 46, parágrafo único, do DL 167; arts. $3^{\circ}$-A, $\S 1^{\circ}, 3^{\circ}$-B, “caput" e $\S 1^{\circ}$, e $3^{\circ}$-D, “caput", da Lei 8.929 ; arts. $3^{\circ}, \S 1^{\circ}, 3^{\circ}$-A, "caput" e $\S 1^{\circ}, 15$, “caput" e $\S 1^{\circ}, 25, \S 1^{\circ}, 27, \S 1^{\circ}, 35,35-A, 35-B$, “caput” e $\S 1^{\circ}$, e $37, \S 1^{\circ}$, da Lei 11.076; arts. 18, § 2º , e 19, “caput”, da Lei 13.986).

A escrituração abrange todos os atos relativos ao título, tais como emissão, negociação ou endosso, aditamento, retificação, ratificação, notificação, garantia e liquidação ou pagamento (arts. 10-C e 10-D do DL 167; arts. $3^{\circ}-\mathrm{C}$ e $4^{\circ}-\mathrm{B}$, parágrafo único, da Lei 8.929; arts. $3^{\circ}-\mathrm{B}$, parágrafo único, $3^{\circ}-\mathrm{C}, 13$, parágrafo único, 17 , “caput” e $\S 1^{\circ}, 35-\mathrm{C}$, parágrafo único, 35-D e 37, § $1^{\circ}$, da Lei 11.076; arts. 19, § $3^{\circ}$, II, 21, § $1^{\circ}$, e 27 da Lei 13.986). Compete à entidade responsável pela escrituração emitir, inclusive de forma eletrônica, a certidão de inteiro teor do título, inclusive para fins de protesto e de execução judicial (art. 10-B do DL 167 ; art. $3^{\circ}-\mathrm{B}, \S \S 2^{\circ}$ e $3^{\circ}$, da Lei 8.929 ; arts. $3^{\circ}$-A, $\S \S 2^{\circ}$ e $3^{\circ}, 35-B, \S \S 2^{\circ}$ e $3^{\circ}$, e $37, \S 1^{\circ}$, da Lei 11.076).

Alguns TCAgro, mesmo se emitidos sob a forma cartular, devem ser custodiados e registrados ou depositados nas entidades autorizadas para serem negociados e terem validade e eficácia: (a) CPR, no prazo de dez dias úteis ${ }^{7}$ (arts. $3^{\circ}$-D, “caput", e 12, “caput" e $\S \S 5^{\circ}$ e $6^{\circ}$, da Lei 8.929); (b) CDA e WA, no prazo de trinta dias (art. 15 da Lei 11.076); (c) CIR, no prazo de cinco dias úteis (arts. 19, “caput” e $§ 1^{\circ}$, e 23 da Lei 13.986). Em todos os casos de emissão cartular, uma vez depositado, o título assumirá a forma escritural; a partir daí, os negócios não devem ser transcritos na cártula e sim lançados no sistema eletrônico (art. $3^{\circ}$-A, $\S \S 2^{\circ}$ e $3^{\circ}$, da Lei 8.929; arts. $3^{\circ}$, $\S 2^{\circ}$, e 19 da Lei 11.076; art. 19, $\S \S 2^{\circ}$ e $3^{\circ}$, da Lei 13.986).

Observe-se que os próprios direitos creditórios vinculados ao CDCA, à LCA e ao CRA devem ser objeto de custódia e registro ou depósito, nos termos dos arts. $25, \S 1^{\circ}$, e 27 , $\S$ $1^{\mathrm{o}}$, da Lei 11.076.

\section{POSSIBILIDADES DE ASSINATURA, REGISTRO E PROTESTO ELETRÔNICOS DOS TÍTULOS DE CRÉDITO DO AGRONEGÓCIO}

\subsection{Possibilidade de assinatura eletrônica}

\subsubsection{Princípio da equivalência funcional entre documentos físicos e eletrônicos}

\footnotetext{
${ }^{7}$ Validade e eficácia da CPR em si, não de suas garantias reais, que devem ser registradas no cartório competente: vide art. $12, \S \S 1^{\circ}, 2^{\circ}$ e $4^{\circ}$, da Lei 8.929 .
} 
A Comissão das Nações Unidas para o Direito Comercial Internacional [United Nations Commission on International Trade Law (UNCITRAL)] adotou, em 1996, a Lei Modelo sobre Comércio Eletrônico (UNITED NATIONS, 1996). Referida Lei consagra dois princípios:

a) Princípio da não discriminação prejudicial (art. $5^{\circ}$ ), segundo o qual:

a um documento não se deve negar a validade jurídica, o efeito ou a aplicação, pelo simples fato de tratar-se de um documento apresentado em forma eletrônica. Ou seja, de acordo com esse princípio, não deve haver qualquer tipo de favorecimento dos documentos apresentados em papel em detrimento daqueles eletronicamente exibidos (POLIDO; SILVA, 2017);

b) Princípio da equivalência funcional (arts. $6^{\circ}, 7^{\circ}$ e $8^{\circ}$ ), segundo o qual:

as comunicações eletrônicas devem ser consideradas equivalentes àquelas feitas em papel sempre e quando seja possível estabelecer que elas cumpram os propósitos e as funções de aspectos inerentes aos documentos em papel, como serem escritos, assinados e originais $(\text { ibidem })^{8}$.

Para Coelho (2010, 2014), o princípio da equivalência funcional entre documentos físicos e eletrônicos é um princípio geral do direito e, portanto, fonte do direito, nos termos do art. $4^{\circ}$ da Lei de Introdução às normas do Direito Brasileiro.

Os arts. 107 do CC e 369 do CPC, de conteúdo "aberto", servem de apoio ao princípio.

\subsubsection{Atos normativos "gerais"}

Existe, hoje, um cipoal de dispositivos e atos normativos conferindo validade jurídica a documentos eletrônicos, para as mais diversas finalidades. No presente trabalho, dar-se-á destaque àqueles atos normativos mais importantes para os TCAgro 9 .

\footnotetext{
${ }^{8}$ Também foi adotado um terceiro princípio, o da neutralidade tecnológica, que "sugere que as regras a serem adotadas pelos Estados sejam as mais neutras possíveis com relação à tecnologia utilizada para o envio das mensagens e documentos, evitando, com sua flexibilidade, novas adaptações legislativas no futuro" (ibidem).

${ }^{9}$ Não serão aqui analisados, mas vale a pena citar os arts. 225 do CC e 411, II, 425, V e VI, e 441 do CPC. Especificamente sobre título de crédito eletrônico, há o art. $889, \S 3^{\circ}$, do CC. Confiram-se ainda os Enunciados 297 e 298 do Conselho da Justiça Federal (IV Jornada de Direito Civil).
} 
Primeiramente, é importante estabelecer a distinção, já existente na doutrina e, inclusive, em alguns atos normativos ${ }^{10}$ : o documento eletrônico ou digital é gênero, do qual são espécies, de um lado, o documento nato-digital, que nasceu eletrônico, e, de outro, o documento digitalizado, que nasceu físico e foi desmaterializado.

3.1.2.1 Atos normativos sobre documentos nato-digitais: MP 2.200-2/2001 e Lei Federal $14.063 / 2020$

Sem dúvida, o marco legal brasileiro que possibilitou as assinaturas eletrônicas foi a Medida Provisória (MP) 2.200-2, de 24 de agosto de 2001.

Referida MP criou um certificado digital baseado na chamada Infraestrutura de Chaves Públicas Brasileira (ICP-Brasil). Seu artigo mais importante é o 10, cujo "caput" e parágrafo primeiro dispõem o seguinte:

Art. 10. Consideram-se documentos públicos ou particulares, para todos os fins legais, os documentos eletrônicos de que trata esta Medida Provisória.

$\S 1^{\circ}$ As declarações constantes dos documentos em forma eletrônica produzidos com a utilização de processo de certificação disponibilizado pela ICP-Brasil presumem-se verdadeiros em relação aos signatários, na forma do art. 131 da Lei $\mathrm{n}^{\circ} 3.071$, de $1^{\circ}$ de janeiro de 1916 - Código Civil. ${ }^{11}$

Referidos dispositivos concretizam a equivalência funcional entre documentos físicos e eletrônicos ao conferir plena validade jurídica aos documentos eletrônicos assinados com o certificado digital emitido no âmbito da ICP-Brasil. Mantém-se, por óbvio, a diferenciação entre documentos públicos e particulares, de acordo com o autor do documento.

Não menos importante é o parágrafo segundo do mesmo Artigo:

$\S 2^{\underline{o}} \mathrm{O}$ disposto nesta Medida Provisória não obsta a utilização de outro meio de comprovação da autoria e integridade de documentos em forma eletrônica, inclusive os que utilizem certificados não emitidos pela ICPBrasil, desde que admitido pelas partes como válido ou aceito pela pessoa a quem for oposto o documento.

\footnotetext{
${ }^{10}$ Cf. art. $2^{\text {o }}$, II, do Decreto Federal 8.539, de 8 de outubro de 2015.

${ }^{11} \mathrm{O}$ dispositivo mencionado corresponde ao art. 219 do atual CC.
} 
Referido dispositivo concretiza o princípio da autonomia da vontade e dá validade jurídica, ainda que inter partes, a outras formas de documentos eletrônicos, por exemplo os assinados com senha, biometria (digital, íris, face) ou certificados não emitidos no âmbito da ICP-Brasil.

A MP 2.200-2/2001 tem força de lei (art. 62, "caput”, da Constituição Federal). Ela não precisou ser convertida em lei por força do art. $2^{\circ}$ da Emenda Constitucional 32, de 11 de setembro de 2001.

Recentemente, as assinaturas eletrônicas ganharam nova regulação com a adoção da Lei Federal 14.063, de 23 de setembro de 2020, que dispõe sobre o uso de assinaturas eletrônicas em interações com entes públicos e dá outras providências.

A grande novidade da Lei está sem seu art. $4^{\circ}$, ao classificar as assinaturas eletrônicas em três tipos: simples, avançada e qualificada. Vale a pena reproduzir o "caput" e o parágrafo primeiro do Artigo:

Art. $4^{\circ}$ Para efeitos desta Lei, as assinaturas eletrônicas são classificadas em: I - assinatura eletrônica simples:

a) a que permite identificar o seu signatário;

b) a que anexa ou associa dados a outros dados em formato eletrônico do signatário;

II - assinatura eletrônica avançada: a que utiliza certificados não emitidos pela ICP-Brasil ou outro meio de comprovação da autoria e da integridade de documentos em forma eletrônica, desde que admitido pelas partes como válido ou aceito pela pessoa a quem for oposto o documento, com as seguintes características:

a) está associada ao signatário de maneira unívoca;

b) utiliza dados para a criação de assinatura eletrônica cujo signatário pode, com elevado nível de confiança, operar sob o seu controle exclusivo;

c) está relacionada aos dados a ela associados de tal modo que qualquer modificação posterior é detectável;

III - assinatura eletrônica qualificada: a que utiliza certificado digital, nos termos do $\S 1^{\circ}$ do art. 10 da Medida Provisória $n^{\circ} 2.200-2$, de 24 de agosto de 2001.

$\S 1^{\circ}$ Os 3 (três) tipos de assinatura referidos nos incisos I, II e III do caput deste artigo caracterizam o nível de confiança sobre a identidade e a manifestação de vontade de seu titular, e a assinatura eletrônica qualificada é a que possui nível mais elevado de confiabilidade a partir de suas normas, de seus padrões e de seus procedimentos específicos.

$[\ldots]$

A assinatura eletrônica do art. 10, § $1^{\circ}$, da MP 2.200-2/2001 (com certificado digital emitido no âmbito da ICP-Brasil) corresponde à assinatura qualificada da nova Lei; a 
assinatura eletrônica do art. $10, \S 2^{\circ}$, da MP corresponde, conforme o caso, à assinatura simples ou avançada da nova Lei.

Cabe ao titular do Poder ou do órgão constitucionalmente autônomo de cada ente federativo estabelecer o nível mínimo exigido para a assinatura eletrônica em documentos e em interações com referido Poder ou órgão (art. 5', "caput"). Nitidamente, a assinatura eletrônica simples será admitida em documentos e interações de importância "menor", a assinatura eletrônica avançada em documentos e interações de importância "menor" ou "média" e a assinatura eletrônica qualificada em documentos e interações de qualquer nível de importância ("menor", "média" ou "maior") - (art. 5, §§ $1^{\circ}, 2^{\circ}$ e $\left.5^{\circ}\right)$.

3.1.2.2 Normas sobre documentos digitalizados: Lei Federal 12.682/2012 e arts. 30 "caput", X, e 18 da Lei Federal 13.874/2019, regulamentados pelo Decreto Federal 10.278/2020

O Decreto Federal 10.278, de 18 de março de 2020, regulamenta tanto a Lei Federal 12.682/2012 (em especial seu art. $2^{\circ}$-A, nela inserido pela Lei Federal 13.874/2019) como os arts. 3', "caput", X, e 18 da Lei Federal 13.874/2019 (Lei de Liberdade Econômica). Nos termos de seu art. $1^{\circ}$, seu objetivo é "estabelecer a técnica e os requisitos para a digitalização de documentos públicos ou privados, a fim de que os documentos digitalizados produzam os mesmos efeitos legais dos documentos originais".

O Decreto aplica-se a pessoas naturais e jurídicas, de direito público ou privado (art. $2^{\circ}$, “caput”); ele não se aplica a documentos nato-digitais (art. $2^{\circ}$, parágrafo único, I).

O documento digitalizado, público ou particular, equipara-se a documento físico para todos os efeitos legais, inclusive para a comprovação de qualquer ato perante pessoa jurídica de direito público interno, se: (a) for "assinado digitalmente com certificação digital no padrão da Infraestrutura de Chaves Públicas Brasileira - ICP-Brasil, de modo a garantir a autoria da digitalização e a integridade do documento e de seus metadados"; (b) "seguir os padrões técnicos mínimos previstos no Anexo I" do Decreto; e (c) “conter, no mínimo, os metadados especificados no Anexo II" do Decreto (art. $5^{\circ}$ e $6^{\circ}$, parágrafo único, do Decreto, regulamentando os arts. $2^{\circ}$-A, “caput” e $\S \S 1^{\circ}, 2^{\circ}$ e $8^{\circ}$, e $4^{\circ}$ da Lei Federal 12.682/2012, bem como os arts. $3^{\circ}, \mathrm{X}$, e 18, II, da Lei Federal 13.874/2019). Já no caso de documento digitalizado que envolva relações entre particulares, se não houver o preenchimento dos requisitos acima, "qualquer meio de comprovação da autoria, da integridade e, se necessário, da confidencialidade [...] será válido, desde que escolhido de comum acordo pelas partes ou 
aceito pela pessoa a quem for oposto o documento" [art. 6", "caput", do Decreto, regulamentando o art. 30 "in fine", da Lei Federal 12.682/2012 (confronte-se a redação antiga com a nova do dispositivo), e o art. 18, I, da Lei Federal 13.874/2019]. Após o processo de digitalização realizado conforme o Decreto, o documento físico poderá ser descartado, ressalvado aquele que apresente conteúdo de valor histórico (art. $9^{\circ}$ do Decreto). A manutenção e a preservação dos documentos digitalizados seguem as regras dos arts. 10, 11 e 12 do Decreto.

\subsubsection{Assinatura eletrônica dos títulos de crédito do agronegócio}

Como visto na Seção 2.6 acima, a Lei do Agro passou a admitir que todos os TCAgro sejam emitidos sob a forma cartular ou escritural ${ }^{12}$. A emissão escritural é, nos dias de hoje, naturalmente eletrônica, enquanto a emissão cartular também pode sê-lo ${ }^{13}$.

Preveem a assinatura ou emissão eletrônica dos TCAgro, cartulares ou escriturais, os seguintes dispositivos: arts. 10-A, "caput”, 14, IX, 20, IX, 25, X, 27, VIII, 42, § 2 , 43, VIII, 46, parágrafo único, e 48, XI, do DL 167 (CR, NPR e DR); arts. 3, “caput”, VIII e $\S 4^{\circ}$, e $3^{\circ}$ A, $\S 1^{\circ}$, da Lei $8.929(\mathrm{CPR})$; arts. $3^{\circ}, \S 1^{\circ}, 35-\mathrm{A}$, e 37 , $\S 1^{\circ}$, da Lei 11.076 (CDA/WA, CDCA e CRA $)^{14}$. O art. $3^{\circ}, \S 4^{\circ}$, da Lei 8.929 merece ser transcrito:

No caso de emissão escritural, admite-se a utilização das formas previstas na legislação específica quanto à assinatura em documentos eletrônicos, como senha eletrônica, biometria e código de autenticação emitido por dispositivo pessoal e intransferível, inclusive para fins de validade, eficácia e executividade. (Incluído pela Lei $n^{o} 13.986$, de 2020)

De qualquer forma, seja a emissão cartular, seja escritural, a Lei do Agro apenas reforçou a normativa "geral" acima mencionada, ou seja, os TCAgro, sem nenhum prejuízo de sua validade e eficácia jurídicas, podem ser:

\footnotetext{
${ }^{12}$ Repita-se: a exceção é o CRA, que só admite a forma escritural (art. 37, § $1^{\circ}$, da Lei 11.076).

${ }^{13}$ Sobre a possibilidade de uma "cártula eletrônica" ou "incorpórea", isto é, um título de crédito que contenha todos os requisitos legais e seja assinado com certificado digital no padrão da ICP-Brasil, e, inclusive, receba aceite, aval e endosso dessa mesma forma: FREIRE JÚNIOR; MAGALHÃES, 2016; MICHELI, 2014; PARENTONI, 2014; PENTEADO, 2003. Cf. ainda Enunciado 462 (V Jornada de Direito Civil) do Conselho da Justiça Federal (com fulcro no art. 889, $\S 3^{\circ}$, do CC) e arts. 571 e 635, parágrafo único, do Projeto de Lei do Senado 487/2013 (Projeto do novo Código Comercial).

${ }^{14} \mathrm{O}$ art. 35 da Lei 11.076 e o art. $18, \S 2^{\circ}$, da Lei 13.986 preveem a emissão escritural, respectivamente, da LCA e da CIR, mas sem especificar o modo eletrônico. Como dito, entretanto, a emissão escritural, no atual estágio de desenvolvimento tecnológico, é naturalmente associada à forma eletrônica (cf. a redação revogada do art. $3^{\circ}$, II, da Lei 11.076).
} 
a) nato-digitais, isto é, emitidos de forma eletrônica, mediante assinatura eletrônica, nos termos da MP 2.200-2/2001 e da Lei Federal 14.063/2020; ou

b) digitalizados, isto é, emitidos de forma física e posteriormente digitalizados, nos termos da Lei Federal 12.682/2012 e arts. 3, "caput", X, e 18 da Lei Federal 13.874/2019, regulamentados pelo Decreto Federal 10.278/2020.

No que se refere à utilização dos três tipos de assinatura eletrônica previstos na Lei Federal 14.063/2020, seja na emissão dos TCAgro (título nato digital), seja na sua digitalização (título digitalizado), é possível concluir que:

a) A assinatura eletrônica simples é válida, exceto no caso da alínea "c" abaixo; entretanto, ela talvez não seja recomendável, tendo em vista a natureza e consequências dos títulos de crédito (como visto, e nos termos da Lei citada, tal tipo de assinatura eletrônica deve ser reservada a documentos e interações de importância "menor" e representam baixo "nível de confiança sobre a identidade e a manifestação de vontade de seu titular"; cf. ainda os arts. 14, IX, 20, IX, 25, X, 27, VIII, 43, VIII, e 48, XI, do DL 167, que aceitam a assinatura eletrônica "desde que garantida a identificação inequívoca de seu signatário”);

b) A assinatura eletrônica avançada é válida, exceto no caso da alínea "c" abaixo;

c) A assinatura eletrônica qualificada é válida em qualquer caso, e obrigatória nos títulos de crédito que impliquem hipoteca, alienação fiduciária ou possibilidade de transferência de propriedade de bem imóvel (art. $5^{\circ}, \S 2^{\circ}$, IV, da Lei Federal 14.063/2020, em interpretação conjunta com o art. 108 do CC) $)^{15}$.

\subsection{Possibilidade de registro eletrônico}

\subsubsection{A relação entre os títulos de crédito do agronegócio e os ofícios de registro de imóveis}

No caso de TCAgro que impliquem hipoteca ou alienação fiduciária de bens imóveis, devem tais garantias ser registradas na matrícula do imóvel hipotecado ou alienado fiduciariamente, nos termos dos arts. 167, I, 2 e 35, da Lei Federal 6.015, de 31 de dezembro de 1973 [Lei de Registros Públicos (LRP)].

\footnotetext{
${ }^{15}$ Inclui-se aqui, portanto, a CIR. Cf. nota de rodapé 16 abaixo.
} 
No caso de TCAgro que impliquem penhor rural, industrial ou mercantil, devem tais garantias ser registradas no registro auxiliar (“livro 3") dos ofícios de registro de imóveis, nos termos dos arts. 167, I, 4 e 15, e 178, IV e VI, da mesma Lei, e arts. 1.438, “caput”, e 1.448, “caput", do CC. Confirmam tal orientação as disposições especiais relativas aos TCAgro: arts. $57,58, \S 1^{\circ}, 61$, parágrafo único, e 62, “caput”, do DL 167 e art. 12 , $\S 1^{\circ}$ e $2^{\circ}$, da Lei 8.929.

A CR e a CPR, em si, não são mais registradas no Registro de Imóveis ${ }^{16}$.

O patrimônio rural em afetação, que possibilita a emissão da CIR, deve ser registrado no Registro de Imóveis (art. $9^{\circ}$ da Lei 13.986). O mesmo ocorre com a transferência de titularidade em caso de inadimplemento da CIR (art. 28 da mesma Lei).

\subsubsection{Possibilidade de registro eletrônico nos ofícios de registro de imóveis}

Com base no art. 76 da Lei Federal 13.465/2017 (e outros aplicáveis a todos os registros públicos, tais como os arts. 37 a 41 da Lei Federal 11.977/2009), a Corregedoria Nacional de Justiça adotou, em 18 de dezembro de 2019, o Provimento 89, que, entre outras coisas, regulamenta o Sistema de Registro Eletrônico de Imóveis - SREI, o Serviço de Atendimento Eletrônico Compartilhado - SAEC e dispõe, ainda, sobre as centrais de serviços eletrônicos compartilhados dos Estados e do Distrito Federal.

Em todos eles - SREI, SAEC e centrais estaduais - devem ser observados os padrões e requisitos de documentos, de conexão e de funcionamento da ICP-Brasil e a arquitetura dos Padrões de Interoperabilidade de Governo Eletrônico (e-Ping) - (arts. 12, 23 e 27, parágrafo único, do Provimento).

O SAEC é uma plataforma eletrônica centralizada que coordena e monitora as centrais estaduais, velando por sua interoperabilidade e visando à universalização do acesso e uniformidade dos serviços (art. 24, $\S 3^{\circ}$ ). Ela destina-se, em primeiro lugar, ao atendimento remoto dos usuários de todas as serventias de registro de imóveis do País por meio da Internet, recepcionando as solicitações de serviços apresentadas pelos usuários remotos e

\footnotetext{
${ }^{16}$ Os ofícios de registro de imóveis possuem dois "livros" para fins de registro: o Livro 2, Registro Geral, para as matrículas dos imóveis, e o Livro 3, Registro Auxiliar, para o registro de outros documentos afetos ao registro de imóveis, por relação natural ou legal. Até há pouco tempo, os oficiais de registro de imóveis faziam dois registros: a) o registro do título, no Registro Auxiliar; e b) o registro da hipoteca ou da alienação fiduciária do imóvel, no Registro Geral (matrícula). Recentemente, foi retirada a obrigatoriedade do registro do documento no Registro Auxiliar (arts. 30 a 40 do DL 167, art. 12 da Lei 8.929, e art. 167, I, 13, da LRP, todos revogados pela Lei do Agro, bem como art. 178, II, da LRP, cuja redação foi alterada pela mesma Lei). O efeito prático é reduzido, uma vez que permanece a necessidade de registro das garantias, nos termos acima.
} 
distribuindo-as às serventias competentes (art. 16). Os serviços eletrônicos oferecidos pelo SAEC são amplos, abrangendo todas as fases do serviço registral imobiliário (art. 18) ${ }^{17}$.

O portal do SAEC é https://www.registrodeimoveis.org.br.

\subsubsection{A relação entre os títulos de crédito do agronegócio e os ofícios de registro de títulos e documentos}

No caso de TCAgro que impliquem penhor comum, de direitos ou de veículos, bem como alienação fiduciária de bens móveis (exceto veículos), devem tais garantias ser registradas nos ofícios de registro de títulos e documentos, nos termos dos arts. 127, "caput", II e IV, e $129,5^{\circ}$ e $7^{\circ}$, da LRP, e $1.361, \S 1^{\circ}, 1^{\text {a }}$ parte, 1.432 , segunda parte, 1.452 , “caput", e 1.462, “caput”, do CC. Nesse sentido vai também o art. 12, § $4^{\circ}$, da Lei 8.929.

Uma exceção é o penhor de direitos constituído pelo CDCA e pela LCA, para cuja constituição não é necessário referido registro (art. 32, “caput”, da Lei 11.076).

\subsubsection{Possibilidade de registro eletrônico nos ofícios de registro de títulos e documentos}

Em 16 de março de 2016, a Corregedoria Nacional de Justiça adotou o Provimento 48, que estabelece diretrizes gerais para o sistema de registro eletrônico de títulos e documentos e civil de pessoas jurídicas. Referido Provimento foi alterado pelo Provimento 59, de 3 de maio de 2017.

Nos termos do art. $2^{\circ}$ do Provimento, o Sistema de Registro Eletrônico de Títulos e Documentos e Civil de Pessoas Jurídicas (SRTDPJ) é integrado por todos os oficiais de registro de títulos e documentos e civil de pessoas jurídicas e compreende, entre outros atos, "a recepção e o envio de títulos em formato eletrônico" (inciso II) e a "expedição de certidões e a prestação de informações em formato eletrônico" (inciso III).

\footnotetext{
17“'Art. 18. O SAEC deverá oferecer ao usuário remoto os seguintes serviços eletrônicos imobiliários a partir de um ponto único de contato na internet: I - consulta de Informações Públicas como a relação de cartórios, circunscrição, tabela de custas e outras informações que podem ser disponibilizadas com acesso público e irrestrito; II - solicitação de pedido que será protocolado e processado pela serventia competente, que compreende: a. Informação de Registro. b. Emissão de Certidão. c. Exame e Cálculo. d. Registro; III acompanhamento do estado do pedido já solicitado; IV - cancelamento do pedido já solicitado, desde que não tenha sido efetivado; V - regularização do pedido quando há necessidade de alteração ou complementação de títulos ou pagamentos referentes a pedido solicitado quando permitido pela legislação; VI - obtenção dos resultados do pedido, que compreende dentre outros: a. Certidão. b. Nota de Exigência. c. Nota de Exame e Cálculo.”
} 
As centrais observarão os padrões e requisitos de documentos, de conexão e de funcionamento da ICP-Brasil e da arquitetura e-Ping (art. $3^{\circ}, \S 7^{\circ}$ ); o mesmo vale para os documentos eletrônicos apresentados aos ofícios de registro de títulos e documentos e civil de pessoas jurídicas, ou por eles expedidos $\left(\operatorname{art} .5^{\circ}\right)$.

Com base no Provimento, o Instituto de Registro de Títulos e Documentos e Pessoas Jurídicas do Brasil (IRTDPJ Brasil) criou a Central Nacional de Registro de Títulos e Documentos e de Registro Civil de Pessoas Jurídicas, que está disponível no endereço eletrônico https://rtdbrasil.org.br.

\subsubsection{Conclusões comuns sobre a possibilidade de registro eletrônico}

Os agentes do agronegócio possuem, assim, a possibilidade de realizar os diversos registros e averbações necessários à eficácia das garantias constituídas por meio dos TCAgro de forma inteiramente eletrônica. Podem ser apresentados os TCAgro nato-digitais ou digitalizados, nos termos acima citados. Podem ser apresentadas, também, as certidões dos TCAgro escriturais, expedidas pelas entidades de escrituração. As normativas são anteriores à Lei Federal 14.063/2020 e não preveem a admissão de títulos assinados com assinatura simples ou avançada, somente qualificada (com uso de certificado digital emitido no âmbito da ICP-Brasil). Há, portanto, necessidade de atualização, tanto dos Sistemas como dos Provimentos $^{18}$.

\subsection{Possibilidade de protesto eletrônico}

\subsubsection{A relação entre os títulos de crédito do agronegócio e os tabelionatos de protesto}

Através da publicização da inadimplência, que ocorre via certidão, site www.pesquisaprotesto.com.br e entidades de proteção ao crédito, os tabeliães de protesto atuam, na prática, como instrumento seguro, eficaz e imparcial de recuperação de crédito.

\footnotetext{
${ }^{18}$ Sottano e Lago (2021) defendem a utilização exclusiva da assinatura eletrônica qualificada em todos os títulos eletrônicos apresentados aos ofícios de registro de imóveis, com fulcro, principalmente, no art. 38, "caput", da Lei Federal 11.977/2009. Tal interpretação contraria e tornaria inócua a norma mais recente - art. $5^{\circ}$, § $2^{\circ}$, IV, da Lei Federal 14.063/2020 - que restringe a exigência aos títulos eletrônicos que impliquem transferência de propriedade. No presente trabalho, admite-se, por exemplo, que os penhores rural, industrial e mercantil sejam constituídos por títulos que utilizem assinatura eletrônica simples ou, preferencialmente, avançada.
} 
Conforme dito acima, os TCAgro são títulos executivos extrajudiciais. São, assim, protestáveis [art. 1º "caput", da Lei Federal 9.492/1997 - Lei do Protesto (LP)]. A possibilidade de recuperação do crédito via protesto, muito mais rápido e eficaz do que a execução judicial, atua em favor tanto do credor (que vê seu crédito recuperado) como do devedor (diminuição dos juros).

\subsubsection{Possibilidade de protesto eletrônico}

Com fulcro no art. 41-A da LP, nela inserido pelo art. $8^{\circ}$ da Lei Federal 13.775, de 20 de dezembro de 2018, a Corregedoria Nacional de Justiça adotou, em 11 de setembro de 2019, o Provimento 87, que dispõe sobre as normas gerais de procedimentos para o protesto extrajudicial de títulos e outros documentos de dívida, regulamenta a implantação da Central Nacional de Serviços Eletrônicos dos Tabeliães de Protesto de Títulos (CENPROT) e dá outras providências.

O protesto por indicação, isto é, sem apresentação do título ou documento de dívida, senão somente com base nas informações prestadas pelo apresentante, já era admitido para duplicatas ${ }^{19}$ e cédulas de crédito bancário ${ }^{20}$. Nos termos do art. $2^{\circ}, \S 1^{\circ}$, do Provimento, todos os títulos ou documentos de dívida passam a poder ser apresentados por indicação, desde que a apresentação seja realizada:

exclusivamente por meio eletrônico, segundo os requisitos da "Infraestrutura de Chaves Públicas Brasileira - ICP Brasil" ou outro meio seguro disponibilizado pelo Tabelionato, autorizado pela respectiva CorregedoriaGeral de Justiça, e com a declaração do apresentante, feita sob as penas da lei, de que a dívida foi regularmente constituída e que os documentos originais ou suas cópias autenticadas, comprobatórios da causa que ensejou a apresentação para protesto, são mantidos em seu poder, comprometendo-se a exibi-los sempre que exigidos no lugar onde for determinado, especialmente se sobrevier sustação judicial do protesto.

A partir do art. 15, o Provimento trata a CENPROT, cujos serviços eletrônicos são amplos, abrangendo todas as fases do protesto de títulos (art. 17, “caput”) ${ }^{21}$.

\footnotetext{
${ }^{19}$ Art. $8^{\circ}, \S 1^{\circ}$, da LP.

${ }^{20}$ Art. 41 da Lei Federal 10.931, de 2 de agosto de 2004.

21،“Art. 17. A CENPROT deve disponibilizar, por meio da rede mundial de computadores (internet) pelo menos, os seguintes serviços: I - acesso a informações sobre quaisquer protestos válidos lavrados pelos Tabeliães de Protesto de Títulos dos Estados ou do Distrito Federal; II - consulta gratuita às informações indicativas da existência ou inexistência de protesto, respectivos tabelionatos e valor; III - fornecimento de informação
} 
O endereço eletrônico da CENPROT nacional é https://site.cenprotnacional.org.br (alternativamente, há os domínios protestodedivida.org.br, www.protestodedividas.org.br e www.pesquisaprotesto.com.br, todos com redirecionamento àquele).

Os agentes do agronegócio possuem, assim, a possibilidade de praticar diversos atos relativos ao protesto de seus títulos de crédito - incluindo apresentação a protesto, desistência do protesto, obtenção do instrumento de protesto, anuência ao cancelamento, cancelamento e certidão - de forma inteiramente eletrônica. Assim como ocorre com relação aos ofícios de registro de imóveis e de títulos e documentos, a normativa é anterior à Lei Federal 14.063/2020. A CENPROT permite a anexação de quaisquer arquivos - inclusive títulos assinados com assinatura eletrônica simples ou avançada - mas seu acesso para fins de apresentação a protesto e a declaração de responsabilidade devem ser realizados com certificado digital emitido no âmbito da ICP-Brasil. Como visto, o Provimento do protesto prevê a possibilidade de se utilizar "outro meio seguro disponibilizado pelo Tabelionato, autorizado pela respectiva Corregedoria-Geral de Justiça”, o que, na prática, ainda não ocorreu.

\section{CONCLUSÃO}

Foram analisados, de forma sucinta e sistematizada, diversos TCAgro: CR, NPR, DR, CPR, CDA/WA, CDCA, LCA, CRA e CIR. Em seguida, foram expostas as possibilidades de assinatura, registro e protesto eletrônicos dos TCAgro. Chegou-se às seguintes conclusões:

a) Vige, como princípio geral do direito, o princípio de equivalência funcional entre documentos físicos e eletrônicos;

b) A MP 2.200-2/2001 e a Lei Federal 14.063/2020 permitem a assinatura eletrônica de quaisquer documentos, com validade jurídica;

complementar acerca da existência de protesto e sobre dados ou elementos do registro, quando o interessado dispensar a certidão; IV - fornecimento de instrumentos de protesto em meio eletrônico; V - recepção de declaração eletrônica de anuência para fins de cancelamento de protesto; VI - recepção de requerimento eletrônico de cancelamento de protesto; VII - recepção de títulos e documentos de dívida, em meio eletrônico, para fins de protesto, encaminhados por órgãos do Poder Judiciário, procuradorias, advogados e apresentantes cadastrados; VIII - recepção de pedidos de certidão de protesto e de cancelamento e disponibilização da certidão eletrônica expedida pelas serventias do Estado ou do Distrito Federal em atendimento a tais solicitações." 
c) O Decreto Federal 10.278/2020, que regulamenta a Lei Federal 12.682/2012 e os arts. $3^{\circ}$, "caput", X, e 18 da Lei Federal 13.874/2019, permite a digitalização de documentos físicos, com validade jurídica;

d) A Lei do Agro passou a admitir que todos os TCAgro sejam emitidos sob a forma cartular ou escritural (exceto CRA, que deve ser escritural); a emissão escritural é, nos dias de hoje, naturalmente eletrônica, enquanto a emissão cartular também pode sê-lo;

e) Os TCAgro, sem nenhum prejuízo de sua validade e eficácia jurídicas, podem ser: (a) nato-digitais, isto é, emitidos de forma eletrônica, mediante assinatura eletrônica, nos termos da MP 2.200-2/2001 e da Lei Federal 14.063/2020; ou (b) digitalizados, isto é, emitidos de forma física e posteriormente digitalizados, nos termos da Lei Federal 12.682/2012 e arts. 30 "caput", X, e 18 da Lei Federal 13.874/2019, regulamentados pelo Decreto Federal 10.278/2020;

f) No que se refere à utilização dos três tipos de assinatura eletrônica previstos na Lei Federal 14.063/2020, seja na emissão dos TCAgro (título nato digital), seja na sua digitalização (título digitalizado), é possível concluir que: (a) a assinatura eletrônica simples é válida, exceto no caso da subalínea "c" a seguir; entretanto, ela talvez não seja recomendável, tendo em vista a natureza e consequências dos títulos de crédito; (b) a assinatura eletrônica avançada é válida, exceto no caso da subalínea "c" a seguir; (c) a assinatura eletrônica qualificada é válida em qualquer caso, e obrigatória nos títulos de crédito que impliquem hipoteca, alienação fiduciária ou possibilidade de transferência de propriedade de bem imóvel (art. $5^{\circ}$, $\S 2^{\circ}$, IV, da Lei Federal 14.063/2020, em interpretação conjunta com o art. 108 do $\mathrm{CC})$;

g) Com base em dispositivos legais e, principalmente, nos Provimentos 59, 87 e 89, da Corregedoria Nacional de Justiça, os agentes do agronegócio podem realizar os diversos registros e averbações necessários à eficácia das garantias constituídas por meio dos TCAgro, bem como praticar diversos atos relativos a seu protesto, de forma inteiramente eletrônica;

h) Toda a normativa acima é anterior à Lei Federal 14.063/2020 e não prevê a admissão de títulos assinados com assinatura simples ou avançada, somente qualificada (com uso de certificado digital emitido no âmbito da ICP-Brasil); há, portanto, necessidade de atualização, tanto dos Sistemas como dos Provimentos; 
no caso específico do protesto, podem ser anexados títulos com assinatura eletrônica simples ou avançada, mas o acesso ao Sistema para fins de apresentação a protesto e a declaração de responsabilidade devem ser realizadas com assinatura qualificada.

\section{REFERÊNCIAS}

BULGARELLI, Waldírio. Títulos de crédito. 16. ed. São Paulo: Atlas, 2000.

COELHO, Fábio Ulhoa. Curso de direito comercial: vol. 1, direito de empresa. 18. ed. São Paulo: Saraiva, 2014. E-book. Segunda parte, Títulos de crédito, Capítulo 15, Outros títulos de crédito, 4, Títulos do agronegócio.

COELHO, Fábio Ulhoa. Títulos de crédito eletrônicos. Entrevista concedida ao Jornal Carta Forense em 02/02/2010. Disponível em: https://washingtonbarbosa.com/2010/02/08/entrevista-fabio-ulhoa-coelho-titulos-de-credito. Acesso em: 27 set. 2021.

COSTA, Wille Duarte. Títulos de crédito. 4. ed. Belo Horizonte: Del Rey, 2008. p. 463-482. (6. tir., 2013).

FREIRE JÚNIOR, Aluer Baptista; MAGALHÃES, Rodrigo Almeida. Teoria geral dos títulos de crédito eletrônicos. Belo Horizonte: D’Plácido, 2016.

MAMEDE, Gladston. Títulos de crédito. 11. ed. São Paulo: Atlas, 2019. p. 161-162, 234$235,238-259$ e $313-331$.

MARTINS, Fran. Títulos de crédito. Atualização de Joaquim Penalva Santos e Paulo Penalva Santos. 17. ed. rev., atual. e ampl. Rio de Janeiro: Forense, 2016. Capítulo XXXIV, títulos de crédito rural, p. 503-532.

MICHELI, Leonardo Miessa de. As duplicatas virtuais como forma de relativização ao princípio da cartularidade. 2014. Dissertação (Mestrado em Direito) - Faculdade de Direito, Universidade São Paulo, São Paulo, 2014. Disponível em: https://www.teses.usp.br/teses/disponiveis/2/2132/tde-03102017-

162817/publico/Dissertacao_Leonardo_Miessa_VERSAO_INTEGRAL.pdf. Acesso em: 27 set. 2021.

NEVES, Rubia Carneiro. Cédula de crédito: doutrina e jurisprudência. Belo Horizonte: Del Rey, 2002.

NEVES, Rubia Carneiro. Uma comparação entre os novos títulos de crédito do agronegócio e as cédulas de crédito. In: FERNANDES, Jean Carlos (org.). Títulos de crédito: homenagem ao Professor Wille Duarte Costa. Belo Horizonte: Del Rey, 2011. p. 203-229. 
PARENTONI, Leonardo Netto. A duplicata virtual em perspectiva. Revista do Tribunal Regional Federal da $3^{\text {a }}$ Região, São Paulo, ano XXV, n. 120, p. 97-128, jan./mar. 2014. Disponível em: https://www.trf3.jus.br/documentos/revs/EDICOES_DA_REVISTA/revista_edicao_120.pdf. Acesso em: 27 set. 2021.

PENTEADO, Mauro Rodrigues. Reflexões sobre os títulos de crédito eletrônicos em face do novo Código Civil. In: ALVIM, Arruda; CÉSAR, Joaquim Portes de Cerqueira; ROSAS, Roberto (coord.). Aspectos controvertidos do novo Código Civil. São Paulo: Revista do Tribunais, 2003, p. 475-490.

POLIDO, Fabrício Bertini Pasquot; SILVA, Lucas Sávio Oliveira da. Contratos internacionais eletrônicos e o direito brasileiro: entre a insuficiência normativa doméstica e as soluções globais. Sequência, Florianópolis, vol. 38, n. 75, p. 157-188, 24 maio 2017. Disponível em: https://periodicos.ufsc.br/index.php/sequencia/article/view/21777055.2017v38n75p157/34026. Acesso em: 27 set. 2021.

REQUIÃO, Rubens. Curso de direito comercial: vol. 2. 29. ed. rev. e atual. por Rubens Edmundo Requião. São Paulo: Saraiva, 2012. E-book. XXXV, Títulos de crédito rural.

SERRA, Márcio Guerra; SERRA, Monete Hipólito. Registro de Imóveis II: atos ordinatórios. São Paulo: Saraiva, 2013. E-book. (Coleção Cartórios; coordenador Christiano Cassettari).

SOTTANO, Augusto; LAGO, Ivan Jacopetti do. As assinaturas eletrônicas e o registro de imóveis: estado atual da questão. In: GALHARDO, Flaviano; PARO, João Pedro; NALINI, José Renato; BRANDELLI, Leonardo (org.). Direito registral e novas tecnologias. Rio de Janeiro: Forense, 2021. E-book.

TOMAZETTE, Marlon. Curso de direito empresarial: títulos de crédito, vol. 2. 8. ed. rev. e atual. São Paulo: Atlas, 2017. p. 52-56, 325-348, 379-391, 403-420, 437-442 e 453-463.

UNITED NATIONS. General Assembly. Resolution 51/162, 16 December 1996. Model Law on Electronic Commerce adopted by the United Nations Commission on International Trade Law. Disponível em: https://uncitral.un.org/sites/uncitral.un.org/files/mediadocuments/uncitral/en/19-04970_ebook.pdf. Acesso em: 27 set. 2021.

UNIVERSIDADE DE SÃO PAULO (USP). Escola Superior de Agricultura Luiz de Queiroz (Esalq). Departamento de Economia, Administração e Sociologia. Centro de Estudos Avançados em Economia Aplicada (CEPEA). PIB do agronegócio Brasil. [apoio financeiro da Confederação da Agricultura e Pecuária do Brasil (CNA)]. Disponível em: https://www.cepea.esalq.usp.br/upload/kceditor/files/Planilha_PIB_Cepea_Portugues_Site_20 20.xlsx. Acesso em: 27 set. 2021. 